\title{
Emergency laparotomy at district hospitals in a developing nation: a review of indications and outcomes of treatment
}

\author{
Aloysius Ugwu-Olisa Ogbuanya ${ }^{1,2,3,4}{ }^{\circledR}$, Nonyelum Benedett Ugwu ${ }^{(\mathbb{D}}$ \\ 'Department of Surgery, Alex Ekwueme Federal University Teaching Hospital, Abakaliki, Ebonyi State, Nigeria \\ 2Department of Surgery, Ebonyi State University (EBSU), Abakaliki, Ebonyi State, Nigeria \\ ${ }^{3}$ Accident and Emergency Unit, Bishop Shanahan Specialist Hostal, Nsukka Enugu State, Nigeria \\ ${ }^{4}$ Department of Surgery, Mater Misericordie Hospital, Afikpo, Ebonyi State, Nigeria
}

\begin{abstract}
Received: 12 February 2021
Accepted: 22 May 2021

Published online: 1 June 2021

* Corresponding author:

Ogbuanya Aloysius Ugwu-Olisa,

Address: Department of Surgery,

Alex Ekwueme Federal University

Teaching Hospital, PMB 102,

Abakaliki, Ebonyi State, Nigeria.

Email:ogbuanyaa92@gmail.com

Competing interests: None.

Funding information: None declared.

Citation: Ogbuanya AU, Ugwu NB. Emergency laparotomy at district hospitals in a developing nation: a review of indications and outcomes of treatment. Journal of Emergency Practice and Trauma 2021; 7(2): 111 117. doi: 10.34172/jept.2021.06.
\end{abstract}

\begin{abstract}
Objective: Recently, emergency and essential surgical and anesthesia care at district hospitals is increasingly gaining recognition as a critical, though neglected element of health care system in Africa and other developing nations. Emergency laparotomy is a versatile procedure that can cure a great deal of acute abdominal conditions. The aim of this study was to document the indications and outcomes of laparotomy for emergency abdominal surgical conditions in our district hospitals.

Methods: This retrospective study was undertaken in district hospitals from January 2009 to December 2018. Associations between different variables were measured and compared using statistical tests of significance.

Results: Of the 879 patients evaluated, appendicitis ( $n=361,41.1 \%)$ was the most frequent indication for emergency laparotomy followed by complicated external hernias $(n=120$, $13.7 \%)$. Other indications were adhesive intestinal obstruction $(n=111,12.6 \%)$, typhoid perforation $(n=98,11.1 \%)$, perforated peptic ulcer $(n=89,10.1 \%)$, trauma $(n=58,6.6 \%)$, colorectal cancer (CRC) $(n=18,2.0 \%)$ and others $(n=24,2.8 \%)$. The vast majority of patients $(n=726,82.6 \%)$ were presented after 24 hours of the onset of disease. Approximately, onethird of patients $(n=278,31.6 \%)$ had comorbidities, 867 (98.6\%) had high ASA scores (III and IV) and 105 (11.9\%) received intestinal resection with or without stoma. The main independent predictors of mortality were late presentation $(P=0.003)$, generalized peritonitis $(P=0.001)$, bowel resection $(P=0.000)$ and high ASA (III and IV) scores $(P=.000)$. Overall, the mortality rate was $10.6 \%$. The commonest complication was wound infection (39.7\%), followed by intra-abdominal collection (10.0\%).

Conclusion: The most common indication for emergency laparotomy was appendicitis followed by complicated hernias. The major independent predictors of mortality included bowel resection, high ASA score, late presentation and generalized peritonitis.

Keywords: Abdominal, Laparotomy, Outcomes, Peritonitis, Resection
\end{abstract}

\section{Introduction}

There is emerging evidence indicating that up to five billion people do not have access to safe, affordable surgical and anesthesia care and majority of these people reside in low- and middle-income countries (LMICs) where one-third of the world's population lives $(1,2,3)$. This is particularly important in the emergency setting, because minutes or hours of delay before effective surgical care have a profound negative impact on outcomes and survival rates $(1,3)$. On average, across sub-Saharan Africa, a population of 10000 is served by two doctors and 11 nursing and midwifery personnel, compared to 32 and 79 respectively serving the same number of people in
Europe (4). Consequently, reports show that 143 million additional surgical procedures are needed in LMICs each year to save lives and prevent disability $(1,4)$. Therefore, without urgent and accelerated investment in surgical scale-up, LMICs will continue to have losses in economic productivity, estimated cumulatively at US $\$ 12.3$ trillion between 2015 and $2030(1,5)$.

Recently, emergency and essential surgical and anesthesia care at district hospitals is increasingly being recognized as a critical, but neglected and deplorable element of health systems in developing countries, especially in Africa $(1,2,3,6)$. Currently, in response to the above, the "Lancet Commission on Global Surgery" and 
the World Bank's “Essential Surgery Package” recommend that basic emergency and essential general surgical procedures should be available at the district hospital level $(2,6-8)$. Importantly, the global population is ageing and many LMICs are facing rapidly growing and urbanizing societies with attendant increases in trauma and neoplasiarelated emergencies in addition to infection-related causes $(1,3)$. This changing pattern requires the general surgeon and health care system to adapt in approach and resource allocation to meet the needs of people requiring emergency surgery $(3,6)$. Traditionally, district hospitals tend to be more accessible than regional hospitals in our setting because of their nearness to the rural and semiurban dwellers. In a resource-limited setting like rural southeast Nigeria with restricted or no access to an emergency transport system, the impact of distance on the decision of patients and their families of whether or not care will be sought is even more worrisome (6).

Worldwide, appendicitis, bowel obstruction, abdominal injuries, strangulated hernias, acute biliary pathology and peritonitis remain the most common causes of abdominal surgical emergencies in adults (3,9-11). Across the globe, the indications for emergency laparotomy vary from region to region and even within the same geographic area, cultural and socio-demographic factors influence the pattern and outcomes of treatment $(2,9,12)$. At the global level, appendicitis is the commonest indication for emergency abdominal operation, but incidentally, on the region to region basis, the order of occurrence has been observed to be subject to performance variation with location of the hospital playing important roles in etiological spectrum, severity and outcomes of management $(1,3,13,14)$. In some regions, trauma cases are more common than appendicitis, but in other series, appendicitis remained the most common pathologic cause $(9,13,14)$. Historically, intestinal obstruction from strangulated inguinal hernia was the leading cause of acute abdomen in developing countries, but recently, the trend has shifted towards acute appendicitis $(9,11,13)$. In recent time, however, evidence from published clinical studies showed that adhesive intestinal obstruction and abdominal trauma have emerged as major causes of emergency abdominal presentations in the West African sub-region and have indeed surpassed strangulated external hernia $(10,13)$.

Data on emergency abdominal operations in rural southeast Nigeria are scanty and the existing data from urban southeast Nigerian hospitals no longer satisfy the clamor by the World Health Organization (WHO) for robust clinical data on safe surgical and anesthesia care in the district hospitals in developing nations $(1,4,8)$. More so, patients in developing nations (sub-Saharan African countries inclusive) commonly present late to the surgeon after several delays at prehospital stage and delay engendered by late referral by non-surgeon physicians $(11,15,16)$. Therefore, delayed treatment of patients with acute abdominal conditions especially when accompanied with comorbid medical diseases, of which patients are often unaware, make management of abdominal emergencies very challenging in many communities across Africa and other LMICs $(1,2,9,13,15)$. The situation is likely to be more deplorable in the rural setting of sub-Saharan Africa due to numerous socio-cultural barriers against orthodox treatment, poverty and poor road networks $(1,13,15)$. This is the first regional study to look in the direction of the etiological spectrum of acute abdominal emergencies and treatment outcomes among rural dwellers of southeast Nigeria. The aim of this study was to document the indications and outcomes of laparotomy for emergency abdominal conditions in district hospitals in southeast Nigeria. It is hoped that data from this study will improve the understanding of the common indications for emergency laparotomy that will guide health managers and government to make informed decision based on the current state of the art.

\section{Methods}

This was a 10-year retrospective study of patients who underwent emergency exploratory laparotomy for various emergency abdominal conditions from January 2009 to December 2018. All the patients were managed in three district hospitals selected for this study.

Initially, the case files of the patients with emergency abdominal conditions within the period of review were retrieved from the Records departments and the diagnoses were noted. Those who had emergency laparotomy within the period under review were selected and the specific diagnoses were recorded. Those with incomplete clinical details were excluded. Details of their socio-demographic characteristics, duration of symptoms before presentation, pre-morbid surgical and medical illnesses, type of primary pathology (indication for laparotomy) and major presenting clinical symptoms and signs were documented. In addition, the anesthetic technique, laparotomy access, intra-operative findings, procedures performed, postoperative outcomes and length of hospital stay were all retrieved and recorded. The length and reports during follow up of available patients were noted. The duration of follow up ranged between one to 18 months.

Data analysis was done with Statistical Package for Social Sciences (SPSS) software version 22.0 (IBM, Chicago, IL USA, 2015). Data were presented as means, tables, percentages and standard deviation. Confidence interval was calculated at 95\% level and significance at 5\% probability level. Associations between different variables were measured and compare using statistical tests of significance.

\section{Results}

During the period under review, 1146 (25.1\%) out of the 4,566 patients with emergency presentations had acute abdomen that required urgent laparotomy. Of the 
4566 emergency cases, 2161 (47.3\%), 1775 (38.9\%), 221 (4.8\%), $216(4.7 \%)$ and 193 (4.2\%) patients had obstetric/ gynecologic, general surgical, orthopedic/plastic, urologic and other emergencies, respectively. Of the 1,775 general surgical cases, there were 1146 acute abdominal emergencies. Therefore, acute abdomen represented $64.6 \%$ of all general surgical emergencies during the study period. Of the 1146 patients with acute abdomen, $899(78.4 \%)$ were managed operatively. The rest, 166 (14.5\%), $33(2.9 \%)$ and $48(4.2 \%)$ received conservative treatment, absconded from treatment, and died before surgical operation, respectively. Nearly a third (52, 31.3\%) of those managed conservatively had adhesive intestinal obstruction. Out of the 899 patients who had operative treatment, clinical details were incomplete in 20 case files. Only the 879 patients with complete clinical details were further evaluated and they formed our study population. There were 588 (66.9\%) males and 291 (33.1\%) females giving a male to female ratio of $2: 1$. The ages of the patients ranged from 16-82 years with a mean of $40.60 \pm$ SD 16.73. Majority of the patients $(n=641,72.9 \%)$ were farmers followed by artisans $(104,11.8 \%)$; the rest were traders (76, 8.6\%), professionals $(20,2.3 \%)$, unskilled laborers $(10,1.1 \%)$, students $(10,1.1 \%)$ and others $(18,2.0 \%)$. The relationship between age and indications for emergency laparotomy is shown below (Table 1).
Over four-fifth of patients $(n=726,82.6 \%)$ presented after 24 hours following the onset of acute symptoms. The duration ranged from 2 hours to 16 days with a median of 5.2 days. Nearly a third of patients $(n=278,31.6 \%)$ had comorbidities ranging from hypertension $(n=141$, $16.0 \%)$, obesity $(n=72,8.2 \%)$, diabetes mellitus $(n=28$, $3.2 \%)$, benign prostatic hyperplasia $(n=18,2.0 \%)$, chronic obstructive pulmonary disease $(n=10,1.1 \%)$, chronic renal failure $(n=4,0.5 \%)$, HIV/AIDS $(n=3,0.3 \%)$ and goiter $(n=2,0.2 \%)$. Over the period of 10 years, there was an upward trend in the annual rates of appendicitis, adhesive bands, perforated peptic ulcer disease (PUD), trauma, and colorectal cancer (CRC). However, there was a downward trend for strangulated external hernias; for typhoid perforation, the trend remained relatively unchanged (Table 2). At the time of presentation, all patients $(n=879,100.0 \%)$ complained of abdominal pain. However, 864 patients (98.3\%) had abdominal tenderness on palpation. Additionally, vomiting, constipation, abdominal distension, fever and tachycardia were present in $671(76.3 \%), 638$ (72.6\%), 739 (84.1\%), 763 (86.8\%) and $754(85.8 \%)$ of patients, respectively.

The most common indication for emergency abdominal surgery was appendicitis $(n=361,41.1 \%)$. In the appendicitis group, 191 patients $(52.9 \%)$ were males and 170 (47.19) were females, giving male to female ratio

Table 1. Indications of laparotomy in the various age groups

\begin{tabular}{|c|c|c|c|c|}
\hline \multirow{2}{*}{ Indications } & \multicolumn{4}{|c|}{ Frequency } \\
\hline & $10-45$ years & 46-64 years & $>64$ years & Total \\
\hline Appendicitis & 246 & 83 & 32 & 361 \\
\hline Complicated external hernia & 64 & 37 & 19 & 120 \\
\hline Adhesive intestinal obstruction & 45 & 49 & 17 & 111 \\
\hline Typhoid perforation & 48 & 36 & 14 & 98 \\
\hline Perforated peptic ulcer disease & 27 & 41 & 21 & 89 \\
\hline Trauma & 32 & 19 & 7 & 58 \\
\hline Colorectal cancer & 3 & 10 & 5 & 18 \\
\hline Intestinal volvulus & 1 & 2 & 3 & 6 \\
\hline Intussusception & 1 & 2 & 1 & 4 \\
\hline Others & 8 & 4 & 2 & 14 \\
\hline Total & $475(54 \%)$ & $283(32 \%)$ & $121(14 \%)$ & $879(100 \%)$ \\
\hline
\end{tabular}

Table 2. Annual laparotomy rates for the various indications

\begin{tabular}{|c|c|c|c|c|c|c|c|c|}
\hline Year & Appendicitis & External hernia & Bands & Typhoid perforated & Perforated PUD & Trauma & CRC & Others \\
\hline 2009-2010 & 49 & 41 & 12 & 21 & 11 & 5 & 1 & 4 \\
\hline 2011-2012 & 59 & 24 & 18 & 19 & 15 & 8 & 2 & 1 \\
\hline 2013-2014 & 68 & 20 & 19 & 18 & 13 & 10 & 3 & 7 \\
\hline $2015-2016$ & 77 & 19 & 24 & 22 & 21 & 13 & 5 & 3 \\
\hline 2017-2018 & 108 & 16 & 38 & 19 & 29 & 29 & 22 & 7 \\
\hline Total & 361 & 120 & 111 & 98 & 89 & 58 & 18 & 24 \\
\hline Percent & 41.1 & 13.7 & 12.6 & 11.1 & 10.1 & 6.6 & 2.0 & 2.8 \\
\hline
\end{tabular}

Abbreviations: PUD, peptic ulcer disease; CRC, colorectal cancer 
of 1.1:1. Among 361 appendiceal resection specimens, $126(35.0 \%)$ were inflamed but not complicated, while 90 (24.9\%) and 60 (16.6\%) were gangrenous and perforated at the time of operation, respectively. Also, the intraoperative and histological details were not stated in 30 (8.3\%) cases, but in the remaining 55 (15.2\%) patients, histology report was negative. Among the 55 patients with negative histology reports, 8 were males and 47 were females giving negative appendectomy rates of $4.2 \%$ and $27.6 \%$ for males and females, respectively. Majority (44, 93.6\%) of the negative appendectomies in the females occurred in those within the reproductive age, namely 40 years and below.

Surgery for emergency presentation of external abdominal wall hernia was the second most common operation carried out during the study period, representing $13.7 \%$ (120 patients) of the total operations performed. Of the total 120 patients in this group, 25 (20.8\%) had lived with their hernias for 20 years or more before the onset of complications. At the time of presentation, 15 (12.5\%), $65(54.2 \%)$ and 40 patients $(33.3 \%)$ had incarcerated, obstructed and strangulated hernias, respectively. Of the 111 patients with adhesive bands, previous caesarean and gynecologic procedures $(n=48,43.3 \%)$ constituted the most common reasons for presentation. Other previous operations that precipitated adhesive intestinal obstruction are shown below (Table 3). In the trauma group, $32(55.2 \%)$ and $26(44.8 \%)$ patients sustained blunt and penetrating abdominal injuries, respectively. Road traffic accidents (RTA) accounted for three-quarters $(\mathrm{n}=24,75.0 \%)$ of all blunt abdominal trauma followed by fall from height $(n=4,12.5 \%)$, then assault and battery $(n=2,6.25 \%)$ and domestic violence $(n=2,6.25 \%)$. Of 26 patients with penetrating trauma, 11 (42.3\%), 8 (30.8\%), $5(19.2 \%)$ and $2(7.7 \%)$ were due to civilian violence, falling astride sharp objects, RTA and industrial violence, respectively.

Majority of the patients $(n=815,92.7 \%)$ had the operations fixed under general anesthesia, the rest $(\mathrm{n}=64,7.3 \%)$ were operated under spinal anesthesia. The American Association of Anesthesiologists (ASA) scores for the patients were ASA I (7, 0.8\%), ASA II (5, 0.5\%), ASA III $(738,84.0 \%)$ and ASA IV $(129,14.7 \%)$. The vast majority of patients $(n=819,93.2 \%)$ had midline incisions; the remaining 60 patients $(6.8 \%)$ (all had complicated inguinal hernias) received groin incisions. More than

Table 3. Precipitating operations for adhesive intestinal obstruction

\begin{tabular}{lcc}
\hline Precipitating operations & No. & Percent \\
\hline Caesarean section/gynecologic Surgeries & 48 & 43.3 \\
Laparotomy for peritonitis & 36 & 32.4 \\
Laparotomy for intestinal obstruction & 18 & 16.2 \\
Post-appendectomy & 4 & 3.6 \\
Others & 5 & 4.5 \\
\hline
\end{tabular}

a tenth of patients $(\mathrm{n}=105,11.9 \%)$ had bowel resection with or without stoma. Of the 22 patients with splenic injuries, 16 (72.7\%) had splenectomy, while the remaining 6 patients $(27.3 \%)$ had splenic salvage procedures.

The most common complication was wound infection $(\mathrm{n}=349,39.7 \%)$, followed by intra-abdominal collection $(n=88,10.0 \%)$. The relative rates of the various complications and mortality are shown below (Table 4). The overall mortality rate was $10.6 \%$, though the rate was higher in the secondary generalized peritonitis group (14.9\%) compared to those without generalized peritonitis (7.1\%). The impact of secondary generalized peritonitis and other predictors (delayed treatment, comorbidity, bowel resection and ASA scores) on the mortality rates are shown below (Table 5). The length of hospital stay was also longer in those with generalized peritonitis (Table 4). The length of follow up ranged between one to 18 months with a median of 4.3 months.

\section{Discussion}

Emergency laparotomy continues to be a common general surgical procedure and can lead to considerable morbidity and mortality especially in LMICs with inadequate health facilities, limited workforce and poor access to safe emergency surgical and anesthesia care $(1,3,17)$. The patients in the current series were predominantly males, young farmers and artisans aged 45 years and below who resided in the rural and semi- urban settlements with deplorable health-seeking behavior. The above findings are consistent with reports from similar studies carried out in Nigeria $(9,16,18)$ and other developing nations like Tanzania (19), Rwanda (2), Zambia (20), Cameroon (17), India (21) and Pakistan (22). However, similar studies in Turkey (23), UK (24), USA (25) and Norway (26) showed that majority of the patients presented earlier in the course of their illness either to the family physician or surgeon and were more advanced in age; the vast majority being in the 6 th-8th decades of live. The discrepancies in the age range were reported to be related to longer life expectancy in the high human development index (HDI) countries, while the prompt and more predictable health seeking behaviors among patients in the developed nations were thought to be due to greater health awareness and availability of robust national health policies in the western nations compared to resource-poor countries $(1,3,4)$.

In the current study, abdominal surgical emergencies represented $25.1 \%$ of emergency surgical admissions during the period under review. This value is comparable to rates of $18.6 \%-29.5 \%$ quoted in previous tertiary hospital series in sub- Saharan Africa $(2,3,13,14,27)$. From the above, it seems that emergency abdominal admissions constitute a significant workload for general surgeons working in both urban tertiary and district hospitals in sub-Saharan African nations. Indeed, this observation may have informed the recent WHO programs (Bellagio Essential Surgery Group, WHO Safe Surgery Checklist and 
Table 4. Post-operative outcomes

\begin{tabular}{|c|c|c|c|c|}
\hline Outcomes & $\begin{array}{l}\text { Perforated peritonitis } \\
\qquad(\mathrm{n}=389)\end{array}$ & $\begin{array}{l}\text { Non-perforated peritonitis } \\
\qquad(\mathrm{n}=490)\end{array}$ & $\begin{array}{l}\text { Total }(\%) \\
(n=879)\end{array}$ & $P$ value \\
\hline Complications, No. (\%) & & & & 0.000 \\
\hline Wound infection & $208(53.3)$ & $141(28)$. & $349(39.7)$ & - \\
\hline Intra-abdominal collection & $62(15.9$ & $26(5.3)$ & $88(10.0)$ & - \\
\hline Entero-cutaneous fistula & $25(6.4)$ & $13(2.7)$ & $38(5.5)$ & - \\
\hline Sepsis & $26(6.7)$ & $10(2.0)$ & $36(4.1)$ & - \\
\hline Atelectasis & $11(2.8)$ & $5(1.0)$ & $16(1.8)$ & - \\
\hline Acute renal failure & $8(2.0)$ & $6(1.2)$ & $14(1.6)$ & - \\
\hline Burst abdomen & $8(2.0)$ & $3(0.6)$ & $11(1.3)$ & - \\
\hline Recurrent hernia & $6(1.5)$ & $4(0.8)$ & $10(1.1)$ & \\
\hline Incisional hernia & $24(6.2)$ & $14(2.9)$ & $38(4.3)$ & - \\
\hline Others & $11(2.8)$ & $6(1.2)$ & $17(11.9)$ & - \\
\hline Mortality, No. (\%) & $58(14.9)$ & $35(7.1)$ & $93(10.6)$ & 0.012 \\
\hline Length of hospital stay (days), $n$ & & & & 0.004 \\
\hline $1-3$ & 0 & 48 & 48 & - \\
\hline $4-7$ & 106 & 334 & 440 & - \\
\hline $8-14$ & 211 & 78 & 289 & - \\
\hline$>14$ & 72 & 30 & 102 & - \\
\hline
\end{tabular}

Table 5. Clinical predictors of mortality

\begin{tabular}{lccc}
\hline Clinical parameter & N & $\begin{array}{c}\text { No of deaths } \\
\text { (mortality rate, \%) }\end{array}$ & P value \\
\hline Duration (h) & 153 & $3(2.0)$ & 0.003 \\
\hline $0-24$ & 258 & $16(6.2)$ & \\
\hline $25-48$ & 468 & $74(15.8)$ & \\
\hline$>48$ & & & 0.001 \\
\hline Generalized peritonitis & 389 & $58(14.9)$ & \\
\hline Present & 490 & $35(7.1)$ & 0.000 \\
\hline Not present & & & \\
\hline Comorbidity & 278 & $38(13.7)$ & \\
\hline Present & 601 & $55(9.2)$ & \\
\hline Not present & & & \\
\hline Bowel resection & 105 & $42(40.0)$ & 0.000 \\
\hline Present & 774 & $51(6.6)$ & \\
\hline Not present & 129 & $62(8.4)$ & \\
\hline ASA class & 738 & & \\
\hline ASA I-II & & & \\
\hline ASA III & & & \\
\hline ASA IV & & & \\
\hline Abbrevian & & & \\
\hline
\end{tabular}

Abbreviation: ASA, American Society of Anesthesiologists.

Global Initiative for Emergency and Essential National Surgical, Obstetrical and Anesthetic Plan-NSOAP) that primarily aimed to promote safe surgical care and upscale access to safe surgical and anesthesia services in LMICs $(1,4,8)$.

Appendix was the most common indication for emergency laparotomy and the most frequent cause of generalized peritonitis in this study. Hitherto, intestinal obstruction from strangulated external hernias was the most frequent indication in the West African subregion, but an epidemiological shift occurred in favor of appendicitis in a manner akin to the Western pattern (9,11,13,16,27-30). The reasons adduced included westernization of lifestyle, increased rates of elective repair of external hernia and general improvement in data documentation and access to surgical care in the sub-region $(2,11,13,27)$. Despite improvements in the diagnostic facilities and clinical knowledge of the pathophysiology and treatment of appendicitis, the disease has remained a significant cause of morbidity and mortality globally $(13,17,28,29)$. The main problem with appendicitis lies with its propensity towards complications like gangrene, rupture, neoplastic growth or mucocele formation $(2,13,19,28)$. In our environment and other LMICs, pre-operative clinical evaluation of patients with suspected acute appendicitis is even more challenging due to an avalanche of differential diagnoses, especially the common tropical enteric infections like salmonella enteritis, ameboma, caecal tuberculosis, intestinal actinomycosis and pyogenic or viral hepatitis $(3,17,10,13,28)$. Furthermore, caecal pole tumor is an important differential diagnosis and must be ruled out in the middle-aged and elderly patients with suspected appendicitis (11-13,28). Consequently, missed and late diagnosis are common, leading to high morbidity and mortality when complications set in $(2,3,9,11,13,17,28)$. Elsewhere, the reported death rate in the event of perforation or gangrene varied between 12\%-33\% (28).

In the developed economy, the assessment and 
management of patients with suspected appendicitis has undergone tremendous evolution. The use of laparoscopy and natural orifice transluminal endoscopic surgery (NOTES) has added flavor to the overall clinical management of the appendiceal diseases (29). In the West, adverse postoperative aftermaths and death rates from appendicitis are considerably lower due mainly to early operation and availability of modern therapeutic facilities like NOTES and laparo-endoscopic techniques (13,28,29 ) .

Complicated external hernia was the commonest indication for emergency laparotomy in the intestinal obstruction group and overall, the second most common indication for emergency laparotomy in this study. In a recent publication in southeast Nigeria, emergency external hernia presentation occupied a distant 5 th position (13). The implication of this finding is that elective repair of abdominal wall hernia in rural southeast Nigeria is still too low to prevent the development of complications compared to the rate of elective hernia repair in central hospitals in southeast Nigeria. In summary, the unmet need for external abdominal wall hernia burden is still huge across most communities in sub-Saharan Africa and calls for an expanded system-wide approach to upscale rates of elective repairs.

In this review, the other three common indications for emergency laparotomy were typhoid perforation, perforated PUD and abdominal trauma (Tables 1 and $2)$. These results are consistent with data from similar studies in Nigeria $(9,10,11,12,13)$ and other parts of subSaharan Africa $(2,27)$. It has been reported that secondary generalized peritonitis (typhoid perforation, perforated or gangrenous appendicitis, perforated PUD) and abdominal trauma pose a considerable challenge in LMICs despite decreasing rates and improvement in morbidity and mortality rates in the high HDI nations $(1,4,17,20-26)$. In a recent publication from a referral hospital in Cameroon, Alain and colleagues observed that the order of frequency of secondary peritonitis in sub-Saharan Africa was: perforated PUD, complicated appendicitis, post-operative peritonitis, typhoid perforation and abdominal injuries (17). However, the mortality toll was highest in the typhoid perforation group, followed by postoperative peritonitis and then perforated PUD (17). These findings conform uniformly with the results in the present study where the mortality rate was $15.0 \%$ in patients with generalized peritonitis (majority of the deaths occurred in those with typhoid perforation) compared to $7.1 \%$ in those without generalized peritonitis (Table 5). Similarly, post-operative complications $(P=0.000)$ and length of hospital stay $(P=0.012)$ were significantly higher in those with secondary generalized peritonitis. It has been found that generalized peritonitis initiates systemic disturbances that often overwhelm the patients' immune mechanisms which subsequently predispose to dangerous rates of morbidity and mortality $(4,14,17,18,23-26)$.

In this study, patients with generalized secondary peritonitis carried significantly higher risk of postoperative mortality compared to others $(P=0.001)$. Late presentation and subsequent delayed treatment of patients was marked in this study. It is noteworthy that mortality rate was proportional to the duration of delay. The observation that mortality rates of $2.0 \%, 6.2 \%$ and $15.8 \%$ occurred in those who presented within 24 hours, 25-48 hours and beyond 48 hours, respectively supports earlier report that the danger lies with the delay and not in the operation $(11,16,18,23,26)$. Other predictors that carried significantly higher risk of post-operative mortality were bowel resection $(P=0.000)$, high ASA score $(P=0.000)$ and comorbidities $(P=0.041)$.

\section{Limitations of the study}

This study was a retrospective review and some case files contained incomplete data and were not included. Also, the follow-up visits were not properly arranged to allow adequate duration and relevant observations.

\section{Conclusion}

Overall, appendicitis was the most common indication, but complicated external hernias remained the most frequent indication in the intestinal obstruction group. Secondary generalized peritonitis, delayed treatment after 24 hours of onset, intestinal resection and high ASA score carried significantly higher risk of postoperative mortality.

\section{Ethical issues}

The protocol for this study was approved by the Institutional Review Board (IRB) of the hospitals before the commencement of data collection and analysis. The study was conducted in accordance with the "Declaration of Helsinki" and all ethical principles guiding retrospective studies on human subjects were observed. The ethical code numbers are BSSH/AD/EA/19/114 (Bishop Shanahan Specialist Hospital), MMH/IRB/19/23 (Mater Misericordia Hospital) and HFH/ECN/20/04 (Holy Foundation Hospital).

\section{Authors' contribution}

AUO, the principal investigator of the study was involved in the concept and design, drafting the article or revising it critically for important intellectual content. UNB assisted the principal investigator in the data acquisition, manuscript editing and data analysis. All the contributors agreed to be accountable for the accuracy and integrity of all aspects of the study and made final approval of the manuscript for submission.

\section{Acknowledgement}

We sincerely appreciate the medical officers, Dr Ogbonna Vincent and Dr Amah David, the nurses at the Accident and Emergency Department and members of staff in the medical records section of the three hospitals for their assistance during data acquisition. 


\section{References}

1. Meara JG, Leather AJM, Hagander L, Alkire BC, Alonso N, Ameh EA et al. Global Surgery 2030; Evidence and solution for achieving health, welfare and economic development-the Lancet Commission. Lancet 2015; 386:569-624. Available at: http://dx.doi.org/101.1016/s0140-6736(15)60160-x

2. Christophe M, Alexandre N, Yihan L, Bethany LH, Jackline $\mathrm{O}$, Theoneste $\mathrm{N}$ et al. Emergency general surgery in Rwanda district hospitals; a cross-sectional study of spectrum, management and patient outcomes. BMC Surgery 2017; 17:121. DOI: $10.1186 / \mathrm{s} 12893-017-0323-\mathrm{x}$

3. Stewart KP, Khanduri P, McCord C, Ohene-Yeboah M, Uranues $\mathrm{S}$ et al. Global disease burden of conditions requiring emergency surgery. BJS 2014; 101: e9- e22. DOI: 10.1002/bjs.9329

4. Luboga S, Macfarlane SB, Schreeb JV, Kruk ME, Cherian $\mathrm{MN}$, Bergstrom $S$ et al. Increasing Access to Surgical Services in sub- Saharan Africa: Priorities for National and International Agencies Recommendation by the "Bellagio Essential Surgery Group". PLos Medicine 2009; 6(12): e1000200

5. Henry JA, Volk AS, Kariuki SK, Murungi K, Firmalo T, Laibon R et al. Ending Neglected Surgical Diseases (NSDs): Definitions, Strategies and goals for the next decade. Int. J Health Policy Management 2020; (4): 1-8 DOI: 10.34172/ Ijhpm.2020.140

6. Fizan A, Shelly CBA, Afua AJH, Abatanga F, Elias S, Hayley OBA et al. Assessment of surgical and obstetrical care of 10 District Hospitals in Ghana using On-Site Interviews. J Surg Res 2010; 2: 12-18

7. Hendrikson BS, Keeney L, Morrell D, Candela X, John O, Hollenbeak CS et al. Epidemiology and Perioperative Mortality of Exploratory Laparotomy in Rural Ghana. Annals of Global Health 2020; 86(1): 1-7. DOI. https://doi. org/10.5334/aogh.2586

8. Jain D, Sharma R, Redd S. WHO safe surgery checklist: Barriers to universal acceptance. J Anaesthesiol Clin Pharmacol 2018; 34:7-10 DOI: 10.4103/joacp. JOACP-307-16

9. Obonna GC, Arowolo OA, Agbakwuru EA, Etonyeaku AC. Emerging Pattern of Emergency Abdominal Surgeries in Ile-Ife, Nigeria. Nigeria J Surg Sci 2014; 24 (2): 31-5. DOI: 10.4103/1116-5898.149600.

10. Chianakwana GU, Ihgogihu CC, Okafor PIS, Anyanwu SNC, Mbonu OO. Adult Surgical Emergency in a Developing Country: The Experience of Nnamdi Azikiwe University Teaching Hospital, Nnewi, Anambra State, Nigeria. World J. surg 2005; 29: 804-808 DOI: 10.1007/s00268-005-7670-y

11. Ahmed A, Dauda M, Garba S, Ukwenya Y. Emergency Abdominal Surgery in Zaria, Nigeria. SAJS 2010; 48(2): 5962 .

12. Agboola JO, Olatoke SA, Rahman GA. Pattern and Presentation of Acute Abdomen in a Nigerian Teaching Hospital. Niger Med. J 2014; 55: 266-70

13. Ogbuanya AU, Emedike SOC. Abdominal Surgical Emergency in South Eastern Nigeria. Int J Recent Sci Res 2016; 7(4): 10217-10223.

14. Spence RT, Panieri E, Rayne SL. A multicenter evaluation of emergency abdominal surgery in South Africa: Results from the GlobalSurg-1 South Africa Study. SAMJ 2016; 106(2):163-168 DOI: 10.7196/SAMJ.2016.v106i2.10183

15. Ohene-Yeboah M, Dally CK. Strangulated Inguinal Hernia in Adult Males in Kumasi. Ghana Med. J 2014; 48(2):101105. DOI: http://dxrdoi.org/10.4314/gmj.v48i2.8.
16. Ogbuanya AU, Amah D. Delay in Presentation and Challenges of Treatment of Complicated Abdominal Wall Hernia in Rural Southeast Nigeria. Niger J Surg Sci 2018; 28 (2):26-33. DOI: 10.4103/njss.njss-4-20

17. Alain C, Fon TA, Ngowe-Ngowe M. Which cause of diffuse peritonitis is the deadliest in the tropics? A retrospective analysis of 305 cases from the South-West Region of Cameroon. World J Emerg Surg 2016; 11:14. DOI: 10.1186/ s13017-016-0070-9

18. Ugochukwu AI, Amu OC, Nzegwu MA. Ileal perforation due to typhoid fever: Review of operative management and outcomes in an urban center in Nigeria. Int. J surg 2013; 11:218-222. DOI: 10.1016/j.ijsu.2013.01.014

19. Chalya PL, Mabula JB, Koy M, Mchembe MD, Jaka HM, Kabangila R et al. Clinical profile and outcomes of surgical treatment of perforated peptic ulcers in Northwestern Tanzanian: A tertiary hospital experience. World J Emerg Surg 2011; 6:31. DOI: 10.1186/1749-7922-6-31

20. Sondashi KJ, Odimba BFK, Kelly P. A Cross-Sectional Study on Factors Associated with Perforated Peptic Ulcer Disease in Adults Presenting to UTH, Lusaka. Med J Zambia 2011; 38(2): 15-22

21. Jhobta RS, Attri AK, Kaushik R, Sharma R, Jhobta A. Spectrum of Perforation Peritonitis in India: Review of 504 Consecutive Cases. World J Emerg Surg.2006; 1: 26. DOI: 10.1186/1749-7922-1-26

22. Memon AA, Siddiqui FG, Abro AH, Agha AH, Lubna S, memo AS. An audit of secondary peritonitis at a tertiary care University Hospital of Sindh, Pakistan. World J. Emerg. Surg. 2012; 7:6. DOI: 10.1186/1749-7922-7-6

23. Menekse E, Kocer B, Topcu R, Olmez A, Tez M, Kayaalp C. A Practical Scoring System to Predicts Mortality in Patients with Perforated Peptic Ulcer. World J Emerg.Surg.2015;10: 7. DOI: $10.1186 / \mathrm{s} 13017-015-0008-7$

24. Saunders DI, Murray D, Pichel AC, Varley S, Peden CJ. Variation in Mortality after Emergency Laparotomy: The First Report of the UK Emergency Laparotomy Network. BJA 2012; 109(3):368-375. DOI: 10.1093/bja/aes165

25. Solomkin JS, Mazuski JE, Brandley JS, Rodvold KA, Goldstein EJC, Baron EJ. Diagnosis and Management of Complicated Intra-abdominal Infections in Adults and Children: Guidelines by the Surgical Infection Society and the Infections Diseases Society of America. Clinical Infections Disease (CID) 2010; 50:133-164. DOI: 10:1086/649554.

26. Thorsen K, Soreide JA, Soreide K. What Is the Best Predictor of Mortality in Perforated Peptic Ulcer Disease? A population-Based, Multi-variable Regression Analysis Including Three Scoring Systems. J Gastrointest Surg 2014; 18:1261-1268. DOI: 10.1007/s11605-014-2485-5.

27. Hanks L, Lin CP, Tefera G, Seyoum N. Abdominal Surgical Emergencies at Tikur Anbessa Specialized Hospital in Ethiopia; A shifting paradigm. East Cent Afr. J Surg 2013; 19 (1): 90-94

28. Ohene-Yeboah M, Togbe B. An audit of appendicitis and appendectomy in Kumasi, Ghana. WAJM 2006; 25(2): 138143.

29. Bingener J, Ibrahim-Zadar I. Natural Orifice Transluminal Endoscopic Surgery for Intra-abdominal Emergency Conditions. BJS 2014; 101: e80-e89. DOI: 10.1002/bjs.9352.

30. Ogbuanya AU, Emedike SOC. Elective Repair of Uncomplicated Inguinal Hernias in South eastern Nigeria. Asian J Med Sc 2015; 7(2): 90-95. DOI: 10.3126/ajms. v7i2.13349. 